\title{
Hiperspektralni senzori i primjena u šumarstvu
}

\author{
Mario Ančić, Renata Pernar, Fran Bono Cindrić, Ante Seletković, Jelena Kolić
}

\begin{abstract}
Nacrtak - Abstract
Od samoga početka razvoja daljinskih istraživanja ljudi su pokušavali stvoriti alat za proučavanje Zemljine površine $i$ dinamičnih pojava na njoj. Napretkom tehnologije najprije $z a$ vojne, a potom $i$ za istraživačke potrebe, razvijeni su senzori za prikupljanje podataka snimanjem elektromagnetskoga spektra (multispektralni i hiperspektralni). U trenutku kada su postali dostupni za uporabu u civilnoj zajednici, postale su očigledne potencijalne koristi uporabe hiperspektralnih podataka. Razvoj hiperspektralnih senzora slijedio je razvoj računalne tehnologije i napredak softvera za obradu velikoga broja prikupljenih podatka.

Danas se hiperspektralni senzori sve više upotrebljavaju za razne namjene: proučavanje ekosustava, atmosfere, klime, hidrologije, iskorištavanja minerala, načina korištenja zemljišta, zemljišnoga pokrova $i$ vegetacije. Zahvaljujući velikomu broju raznovrsnih informacija koje pružaju, hiperspektralni senzori imaju veliku mogućnost primjene u nadzoru $i$ upravljanja okolišem te pomažu unapređenju upravljanja i donošenju boljih odluka pri ranom definiranju problema.

Prva primjena hiperspektralnih senzora $u$ šumarstou $u$ Hrvatskoj vezana je uz program Europske zajednice iz 2005. godine, kada su provedena proa snimanja linijskim hiperspektralnim senzorom. U sklopu provedenih snimanja izdvojene su prve spektralne krivulje obične jele i bijele imele, na osnovi kojih je proi put izdvojena vrsta unutar vrste, odnosno pomoću hiperspektralnih snimaka razlučeni su grmovi poluparazitske vrste unutar krošanja domaćina te su definirane procedure za snimanja na velikim površinama.
\end{abstract}

Ključne riječi: hiperspektralni senzori, šumarstvo, spektralni potpisi

\section{Uvod - Introduction}

Od sredine 50-ih godina 20. stoljeća razni senzori bilježe reflektirano zračenje sa Zemljine površine $u$ spektru 400-2500 nm. Prvi su senzori bilježili podatke na crnobijeli, a nakon toga na infracrveni kolor (ICK) film (zeleni, crveni i bliski infracrveni kanal). Napretkom digitalnih tehnologija najprije za vojne, a potom za istraživačke potrebe, razvijeni su brojni senzori kojima se prikupljaju podaci u prostranom i širokom spektralnom rasponu. Takvi se senzori nazivaju multispektralni, a od svoga postanka do danas čine okosnicu optičkoga sustava prikupljanja podataka (Lucas i dr. 2004).

Od ranih 70-ih godina 20-oga stoljeća lansiran je velik broj orbitalnih multispektralnih senzora, koji su prikupljali i još uvijek prikupljaju podatke u nekoliko širokih (100-200 nm) spektralnih kanala ne- pravilna prostornoga rasporeda (Van der Meer i De Jong 2001). Takve karakteristike dovode do usrednjavanja spektara ili prekrivanja slabijih značajki jačima (Kumar i dr. 2001), što s ekološkoga stajališta rezultira smanjenje ili gubitak informacija koje je moguće izdvojiti.

Upravo nedostatak prostorne, spektralne i radiometrijske rezolucije mnoge multispektralne senzore čini neadekvatnima za identificiranje materijala i njegovih značajki, a posebno za identificiranje minerala (Goetz 1995).

\section{Hiperspektralni senzori Hyperspectral sensors}

Prepoznavanjem ograničenja multispektralnih senzora razvijene su poboljšane tehnologije teme- 
ljene na spektroskopiji, prilikom čega je ograničeni broj kanala poboljšan primjenom niza uskih graničnih kanala od vidljivoga do termalnoga područja elektromagnetskoga spektra (Aspinall i dr. 2002). Hiperspektralni senzori koriste kontinuirane raspone, za razliku od multispektralnih senzora (slika 1) koji koriste podskup ciljanih valnih duljina određenih dijelova spektra (Veys i dr. 2017). (a)
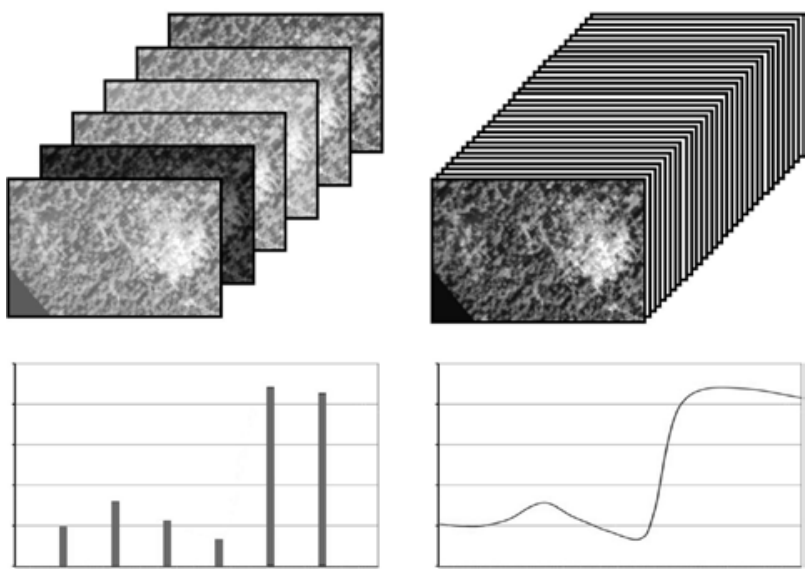

Slika 1. Razlika između multispektralnih (a) i hiperspektralnih (b) senzora

Fig. 1 Difference between multispectral (a) and hyperspectral (b) sensors

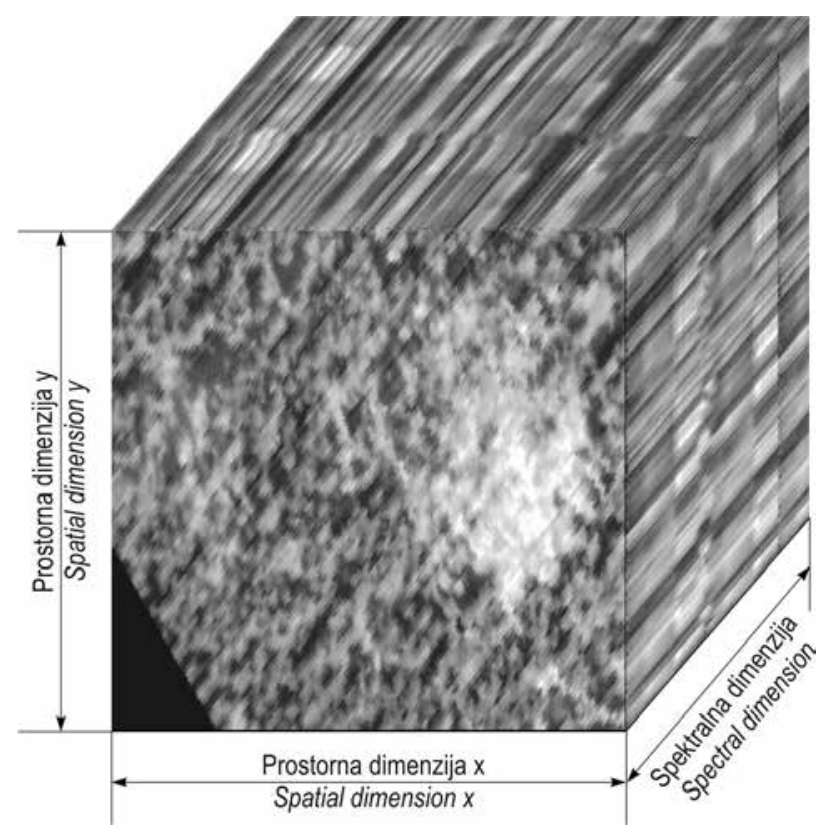

Slika 2. Primjer hiperspektralne kocke (Ančić 2011)

Fig. 2 An example of hyperspectral cube (Ančić 2011)
Hiperspektralnim snimanjem prikupljaju se i obrađuju podaci radi dobivanja spektralne informacije iz svakoga piksela na slici, što omogućuje detekciju i određivanje karakterističnih značajki predmeta i materijala od kojih je taj predmet izgrađen. Matrice spektralnih uzoraka grade se na osnovi snimljenih linija po sustavu linija po linija oblikujući dvodimenzionalnu sliku ( $x$ i $y$ prostorne osi), dok treća $z$ os prikazuje spektralne podatke svakoga snimljenoga piksela ( $\lambda$ os) (Aspinall i dr. 2002). Takav se prikaz naziva hiperspektralnom kockom (slika 2).

Hiperspektralni senzori omogućuju prikupljanje velikoga broja podataka o raznim parametrima $\mathrm{u}$ istraživanju vegetacije i okoliša. Kako bi se pobliže objasnila njihova primjena u istraživanju vegetacije, a pri tome i njegova primjena u šumarstvu, ključno je navesti opisne elemente spektralnih potpisa vegetacije poput green peak, chlorophyll well, red edge i NIR plateau (slika 3) (Kumar 1998, Huber i dr. 2005).

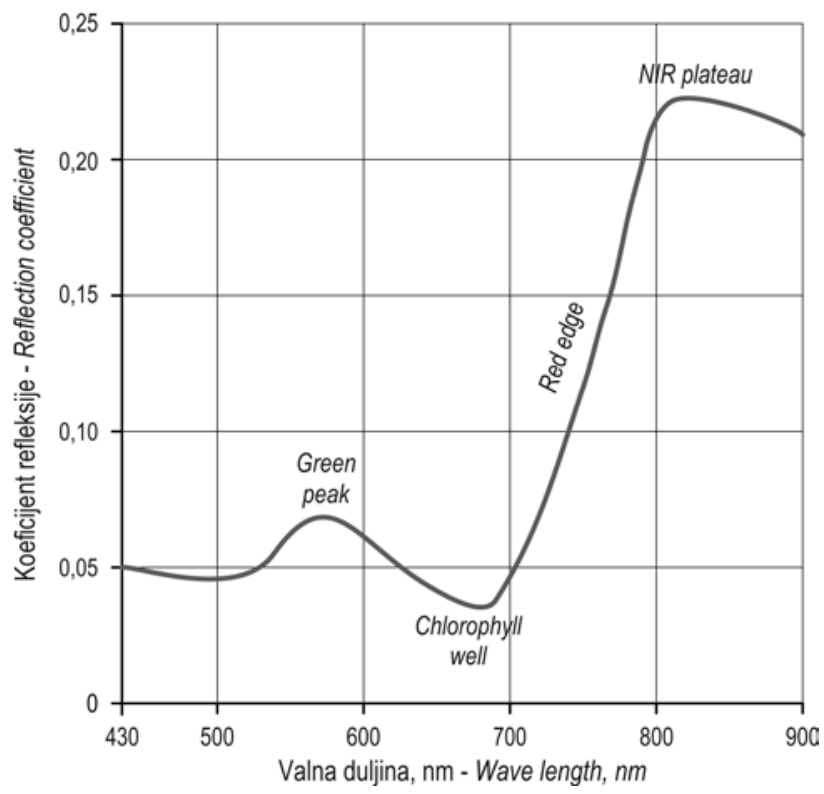

Slika 3. Karakteristična hiperspektralna krivulja za vegetaciju s pojmovima koji ju opisuju

Fig. 3 Characteristic vegetation hyperspectral curve with explanation terminology

Posebno značenje ima red edge koji prikazuje najveću promjenu refleksije s obzirom na promjenu spektralnih značajki bilo kojega zelenoga lista u vidljivom i bliskom infracrvenom području (Elvidge i dr. 1990), koje se obično identificira pomoću točke infleksije crvenoga ruba (red-edge inflection point) ili točkom maksimalnoga nagiba, a nalazi se između 680 i 750 nm, bez obzira na vrstu (Kumar i dr. 2001). 
Pomoću navedenih elemenata spektralnih potpisa, a osobito pomoću obilježja red edge, moguće je razlikovati pojedine vrste jer svaka vrsta ima svoj spektralni potpis.

Prema Buckinghamu i dr. (2002) na hiperspektralnim snimkama apsorpcija i raspršivanje čestica (reflektirano zračenje) formiraju karakteristične potpise (slika 4) i tako omogućuju detekciju objekata.

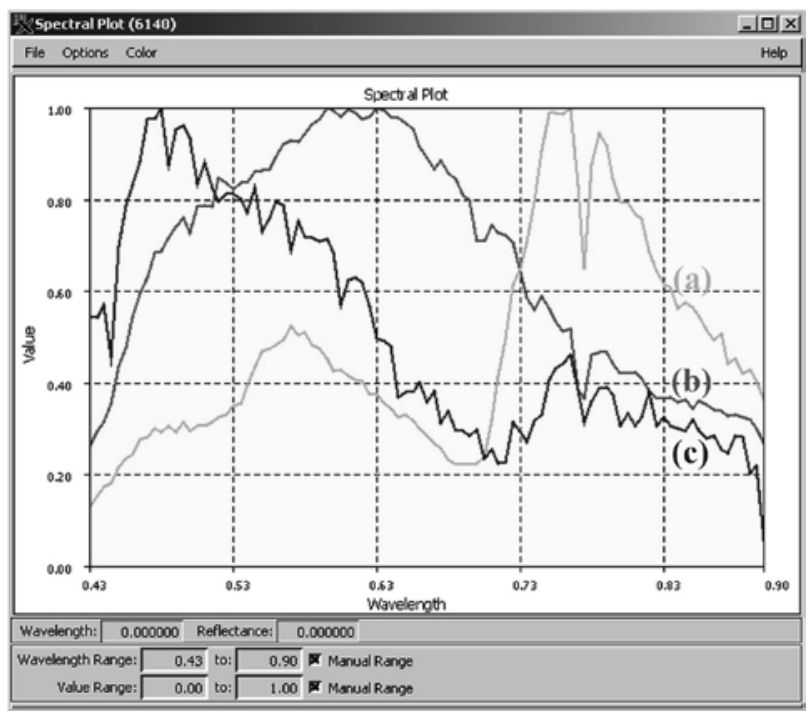

Slika 4. Prikaz spektralnih potpisa za tri spektralna uzorka: (a) vegetacija, (b) kamen i (c) sjena (Ančić 2011)

Fig. 4 Display of spectral signatures for three different spectral patterns (a) vegetation, (b) rock and (c) shadow (Ančić 2011)

Hiperspektralni senzori skeniraju i skupljaju karakteristične svjetlosne "potpise « biljaka - čiste spektralne uzorke (endmembere) minerala i svih ostalih objekata. Čistim spektralnim uzorcima smatramo najekstremnije ili spektralno »čiste« elemente (npr. jela, dolomit i dr.), a oni se najčešće definiraju $\mathrm{u}$ idealnim terenskim ili laboratorijskim uvjetima. U slučaju kada nije moguće terensko mjerenje, endmemberi se mogu izdvojiti iz čistih elemenata snimke (Piwowar 1999). Pretpostavka je da se na snimljenoj sceni nalaze takvi čisti spektralni uzorci te da je prostorna rezolucija u takvu slučaju dovoljno velika $(<1 \mathrm{~m})$ jer se tada povećava mogućnost odabira čistoga uzorka (Ticehurst i dr. 2001, Culvenor 2002, Held i dr. 2003).

Spektralni potpisi vegetacije, za razliku od minerala, dinamični su u spektralnoj, prostornoj i vremenskoj dimenziji te ih s oprezom treba ugraditi u spektralne knjižnice (Elvidge 1990, Salisbury i dr. 1991a, Salisbury i dr. 1991b, Grove i dr. 1992, Clark i dr. 1993, Salisbury i dr. 1994, Korb i dr. 1996, Asner i
Heiderbrecht 2002, Shippert 2003, Lucas i dr. 2004). Upravo na osnovi spektralnih potpisa, unutar velike količine spektralnih informacija prikupljenih hiperspektralnim senzorima, algoritmi mogu identificirati određeni objekt ovisno o njegovu spektralnom potpisu. Za to su ključni čimbenici za određivanje vjerojatnosti dobivanja »čistoga« spektra refleksije, a uključuju prostornu razlučivost senzora, gustoću sklopa, područje i kut distribucije lišća i grana te udio sjena u krošnji (Adams i dr. 1995). U većini slučajeva spektralni je potpis pomiješan sa spektralnim potpisima drugih objekata, no unatoč degradaciji »čiste« spektralne refleksije podaci biokemijskih i biofizičkih svojstava krošanja još uvijek mogu biti prikupljeni. Zahvaljujući tomu, hiperspektralni su se senzori pokazali dobrima za istraživanje vegetacije kao moćan dijagnostički alat.

Hiperspektralni sustavi mogu se podijeliti prema metodama snimanja (whiskbroom - točka po toč$\mathrm{ka}$, pushbroom - linija po linija, the staring approach cijela scena u jednom spektralnom kanalu i snapshot - kompletna spektralna kocka u jednoj snimci) i prema nositeljima/platformama na kojima su postavljeni (satelitski, zrakoplovni, terenski/laboratorijski).

\section{Primjena hiperspektralnih senzora u proučavanju i zaštiti okoliša Application of hyperspectral scanners in environmental studies and protection}

Hiperspektralni su senzori dugi niz godina od pojave imali uporabu u vojne svrhe (Van der Meer i De Jong 2001). Od trenutka kada je tehnologija postala dostupna $\mathrm{u}$ civilnom segmentu nalazi se $\mathrm{u}$ raznim primjenama od zdravstva, obrade hrane, iskorištavanju mineralnih dobara, za potrebe sigurnosnih nadzora, $\mathrm{u}$ astronomiji, ekologiji, prostornom planiranju, šumarstvu, poljoprivredi, arheologiji i dr. (Lucas i dr. 2004).

$S$ obzirom na velike mogućnosti primjene hiperspektralnih podataka u proučavanju i zaštiti okoliša mogu se koristiti za:

$\Rightarrow$ procjenu kvalitete tla i nadzor agrokulturnoga utjecaja (Idowu i dr. 2008)

$\Rightarrow$ taloženje industrijske prašine i čestica iz atmosfere (Ong i dr. 2001)

$\Rightarrow$ detekciju zagađenja tla i vode uglijikovodicima i za nadzor naftnih cjevovoda (Li i dr. 2005)

$\Rightarrow$ nadzor onečišćenja vode (Bianchi i dr. 1995a, Bianchi i dr. 1995b), nadzor kvalitete pitke jezerske vode i nadzor obalnoga područja (Mannheim i dr. 2004) 
$\Rightarrow$ kartiranje biljnih vrsta i staništa, posebno za ugrožene vrste (Clark i dr. 2005, Belluco i dr. 2006)

$\Rightarrow$ izradu karata močvarnih zemljišta (Neuenschwander i dr. 1998, Elhadi i Mutanga 2009)

$\Rightarrow$ nadzor krčenja šuma i degradaciju šumskih površina (De Jong i Epema 2001)

$\Rightarrow$ identificiranje i nadzor štetnih korova (Deguise i dr. 1999)

$\Rightarrow$ nadzor biomase (Cho i dr. 2007) i paljenje biomase (Green i dr. 1998)

$\Rightarrow$ kartiranje invazivnih vrsta (Tsai i Chen 2004)

$\Rightarrow$ kartiranje napada štetnih kukaca (Coops i dr. 2003, Lawrence i Labus 2003, Pontius i dr. 2005, Mirik i dr. 2006)

$\Rightarrow$ kartiranje zdravstvenoga stanja šuma (Pontius i dr. 2005)

$\Rightarrow$ nadgledanje oštećenja rudarenjem i za rehabilitaciju uništenih područja (Chevrel i dr. 2001)

$\Rightarrow$ praćenje ugljika $\mathrm{u}$ inventuri šuma (Andersson $\mathrm{i}$ dr. 2009)

$\Rightarrow$ detekciju sadržaja vode $\mathrm{u}$ vegetaciji (Chisholm 2001)

$\Rightarrow$ otkrivanje potencijalnih žarišta požara (hot spot) i detekciju dima (Robichaud i Zamudio 2004) i dr.

Prednost velikoga broja informacija dobivenih snimanjem hiperspektralnim senzorima $u$ ranoj je detekciji i donošenju odluka za rješavanje problema kojima bi se oni mogli ublažiti ili u potpunosti spriječiti.

\section{Primjena hiperspektralnih senzora $u$ šumarstvu - Application of hyperspectral scanners in forestry}

Povećana potražnja za stalnim monitoringom za opstanak biološke raznolikosti i procjena zdravstvenoga stanja šuma zahtijevala je uvođenje novih tehnologija za istraživanja u šumarstvu - hiperspektralnih senzora.

Postoje mnogi primjeri primjene hiperspektralnoga snimanja za određivanje biokemijskih varijabli dušika i lignina, apsolutnoga sadržaja vode u lišću biljke, za mjerenje koncentracije pigmenta u listovima, mjerenje sadržaja klorofila u biljkama i dr. (Lucas i dr. 2004).

Klorofil u biljkama apsorbira vidljivu svjetlosti, ali plavu i crvenu $u$ jačem intenzitetu od zelene. Takva refleksija zdrave biljke na spektralnim krivuljama stvara karakteristični »vrh« refleksije unutar zelenoga dijela vidljivoga spektra (chlorophyll peak). Smanjenjem vitalnosti biljaka smanjuje se apsorpcija klorofila, što rezultira smanjenjem refleksije u crvenom i bližem infracrvenom području. Pomaci unutar tih dvaju područja najčešće upućuje na stres stabala prikazan na lisnoj masi (Ferretti 1997).

Stres u šumama pokazuje razne simptome od kojih se neki mogu otkriti hiperspektralnim skeniranjem (Stone i Mohammed 2017). Razni su razlozi pogoršanja zdravstvenoga stanja šuma. Kukci, gljivične bolesti, onečišćenje tla, zagađenje zraka, suše, ekstremne vremenske prilike, antropogeni utjecaj i drugi čimbenici izazivaju stres u šumama.

Osim praćenja stanja šuma hiperspektralne se snimke koriste i $\mathrm{u}$ druge svrhe poput monitoringa invazivnih vrsta drveća ili za determinaciju vrsta. Van Aardt i Wynne (2001) dokazali su kako pomoću infracrvenoga dijela spektra izvornih hiperspektralnih podataka mogu prepoznati i determinirati četinjače i listače umjerenoga područja. Slično je istraživanje provedeno 2002. godine pomoću hiperspektralnoga skenera HyMap (Darvishsefat i dr. 2002).

Hiperspektralne snimke, osim navedenih primjena, moguće je koristiti i u druge svrhe (za kartiranja progradacije štetnih kukaca, strukture vegetacije i gorive materije, za otkrivanje mogućih žarišta požara i dr.).

Iz svega navedenoga može se zaključiti kako šumarstvo ima veliku korist od podataka prikupljenih hiperspektralnim senzorima, pogotovo za potrebe praćenja zdravstvenoga stanja šuma i kartiranja vegetacije.

\section{Hiperspektralna istraživanja u šumarstvu Republike Hrvatske Hyperspectral research in forestry in the Republic of Croatia}

Prva hiperspektralna istraživanja u Hrvatskoj započinju u sklopu programa Europske zajednice (projekti ARC i SMART). Tada su, prvi put u hrvatskom šumarstvu, na području Medvednice (NPŠO Zagreb), uz multispektralna, provedena i hiperspektralna snimanja linijskim skenerom ImSpector V9 na vegetaciji, točnije na običnoj jeli i poluparazitskoj vrsti bijela imela. Rezultat su bile prve spektralne krivulje refleksije obične jele i bijele imele (Pernar i dr. 2005).

Nastavkom istraživanja provedeno je snimanje hiperspektralnim linijskim skenerom ImSpector V9 u kontroliranim uvjetima na uzorcima obične jele i bijele imele. Snimanje je rezultiralo izdvajanjem čistih spektralnih potpisa (endmembera) obične jele i bijele 
imele, a izdvojeni čisti spektralni potpisi poslužili su kao referencija za daljnja istraživanja i kontrolu prikupljenih podataka snimanjem iz zraka.

Na području UŠP Gospić 2010. godine obavljeno je snimanje hiperspektralnim skenerom iz zrakoplova. Cilj je istraživanja bio razviti učinkovitu i pouzdanu metodu za detekciju imele na jeli sa što većom pouzdanošću. Istraživanjem je dobiven rezultat kojim je prvi put izdvojena vrsta unutar vrste, odnosno pomoću hiperspektralnih snimki razlučeni su grmovi poluparazitske vrste bijela imela unutar krošanja domaćina obične jele. Formirana je spektralna knjižnica, a izdvojeni spektralni potpisi postali su njezin dio te se mogu uporabiti u budućim istraživanjima (Ančić i dr 2014).

Također je provedeno snimanje hiperspektralnim skenerom $\mathrm{u}$ kontroliranim uvjetima za glavne šumske vrste $u$ RH (hrast lužnjak, običnu bukvu, običnu jelu i smreku) i za dvije poluparazitske biljke (bijela i žuta imela). Provedenim istraživanjem definirani su postupci uzimanja uzoraka i dobiveni spektralni potpisi za istraživane vrste (endmemberi). Spektralni potpisi postali su dio spektralne knjižnice, a najznačajniji rezultat istraživanja jest mogućnost primjene za detekciju vrsta na hiperspektralnim snimkama (Ančić i dr. 2019).

\section{Zaključak - Conclusion}

Napredovanjem tehnologije hiperspektralni se senzori usavršavaju, a njihove snimke postaju dostupne velikomu broju istraživača te pronalaze primjenu u mnogim znanstvenim disciplinama.

Kako u drugim disciplinama, tako i u šumarstvu takav se način snimanja može koristiti za određivanje biomase, kartiranje šumske vegetacije, praćenje zdravstvenoga stanja šuma, progradacije kukaca, širenja gljivičnih bolesti, za mjerenje zaliha ugljika, mjerenje sadržaja klorofila u lišću, za procjenu produktivnosti i dr.

U usporebi s terenskim načinom istraživanja količina povratnih informacija iz hiperspektralnih snimki veća je i ekonomski isplativija za potrebe šumarstva s obzirom na brzinu obavljanja poslova i inventariziranu površinu. No, ne može se reći kako hiperspektralni senzori u potpunosti zamjenjuju terenska istraživanja, već bi se trebali, u sinergiji, nadopunjavati i pomagati pri donošenju bitnih odluka poput provođenja zaštitnih mjera, praćenja stanja ekosustava i dr., te kao takvi pridonijeti pravodobnomu uočavanju negativnih posljedica na šumske ekosustave.

Velika se učinkovitost hiperspektralnih senzora može postići provođenjem kontinuiranoga višego- dišnjega praćenja vegetacije. Mogućnost je primjene hiperspektralnih senzora $u$ svim granama šumarstva velika s obzirom na količinu informacija koju oni mogu isporučiti i na dostupnost. Upravo zbog raznovrsnih mogućnosti hiperspektralnih senzora preporuka je uvoditi ih u operativnu primjenu u šumarstvu.

\section{Literatura - References}

Adams, J.B., D.E. Sabol, V. Kapos, R A. Filho, D.A. Roberts, M.O. Smith, 1995: Classification of multispectral images based on fractions of endmembers: Application to land-cover change in the Brazilian Amazon. Remote Sensing of Environment 52: 137-154. https://doi. org/10.1016/0034-4257(94)00098-8

Andersson, K., T.P. Evans, K.R. Richards, 2009: National forest carbon inventories: policy needs and assessment capacity. Climatic Change 93(1): 69-101. https://doi. org/10.1007/s10584-008-9526-6

Ančić, M., 2011: Primjena multispektralnih i hiperspektralnih snimaka u procjeni oštećenosti obične jele (Abies alba Mill.) i detekciji imele (Viscum album L. ssp. abietis / Weisb./ Abrom.). Disertacija, Šumarski fakultet Sveučilišta u Zagrebu, 161 str.

Ančić, M., M. Bajić, J. Kolić, R. Pernar, A. Seletković, 2014: Detecting mistletoe infestation on Silver fir using hyperspectral images. iForest 7: 85-91. https://doi.org/10.3832/ ifor1035-006

Ančić, M., R. Pernar, M. Bajić, A. Krtalić, A. Seletković, D. Gajski, J. Kolić, 2019: Spektralni potpisi (endmemberi) nekih šumskih vrsta u Republici Hrvatskoj. Šumarski list (u tisku).

Asner, G.P., K.B. Heidebrecht, 2002: Spectral unmixing of vegetation, soil and dry carbon cover in arid regions: comparing multispectral and hyperspectral observations. International Journal of Remote Sensing 23(19): 3939-3958. https://doi.org/10.1080/01431160110115960

Aspinall, R.J., W.A. Marcus, J.W. Boardman, 2002: Considerations in collecting, processing and analysing high spatial resolution hyperspectral data for environmental investigations. Journal of Geographical Systems 4: 15-29. https://doi.org/10.1007/s101090100071

Belluco, E., M. Camuffo, S. Ferrari, L. Modenese, S. Silvestri, A. Marani, M. Marani, 2006: Mapping salt-marsh vegetation by multispectral and hyperspectral remote sensing. Remote Sensing of Environment 105(1): 54-67. https://doi.org/10.1016/j.rse.2006.06.006

Bianchi, R., A. Castagnoli, R.M. Cavalli, C.M. Marino, S. Pignatti, E. Zilioli, 1995a: Preliminary analysis of aerial hyperspectral data on shallow lacustrine waters. Remote Sensing for Agriculture, Forestry and Natural Resources. U: E.T. Engman, G. Guyot, C.M. Marino (ur.): SPIE Proceedings 2585: 341-351. https://doi.org/10.1007/978-3-66205605-9 
Bianchi, R.A., R.M. Castagnoli, C.M. Cavalli, S. Marino, M. Pignatti, M. Poscolieri, 1995b: Use of airborne hyperspectral images to assess the spatial distribution of oil spilled during the Trecate blow-out (Northern Italy). Remote Sensing for Agriculture, Forestry and Natural Resources. U: E.T. Engman, G. Guyot, C.M. Marino (ur.): SPIE Proceedings 2585: 352-362. https://doi.org/10.1007/978-3-662-05605-9

Buckingham, B., K. Staenz, A. Hollinger, 2002: Review of Canadian airborne and space activities in hyperspectral remote sensing. Canadian Aeronautics and Space Journal 48(1): 115-121. https://doi.org/10.5589/q02-013

Chevrel, S., V. Kuosmanen, R. Belocky, S. Marsh, T. Tapani, H. Mollat, L. Quental, P. Vosen, V. Schumacher, E. Kuronen, P. Aastrup, 2001: Hyperspectral airborne imagery for mapping mining-related contaminated areas in various European environments - First results of the MINEO Project. $5^{\text {th }}$ International Airborne Remote Sensing Conference, San Francisco, California, 17-20 September 2001, 8 p.

Chisholm, L.A., 2001: Characterisation and evaluation of moisture stress in E. camaldulensis using hyperspectral remote sensing. Sidney, University of New South Wales, p. 236.

Cho, M.A., A. Skidmore, F. Corsi, S. E. van Wieren, I. Sobhan, 2007: Estimation of green grass/herb biomass from airborne hyperspectral imagery using spectral indices and partial least squares regression. International Journal of Applied Earth Observation and Geoinformation 9(4): 414-424. https://doi.org/10.1016/j.jag.2007.02.001

Clark, R.N., G.A. Swayze, A.J. Gallagher, T.V.V. King, W.M. Calvin, 1993: The U. S. Geological Survey, Digital Spectral Library. Version 1: 0.2 to 3.0 microns. U.S. Geological Survey Open File Report 93-592, p. 1340.

Clark, M.L., D.A. Roberts, D.B. Clark, 2005: Hyperspectral discrimination of tropical rain forest tree species at leaf to crown scales. Remote Sensing of Environment 96: 375398. https://doi.org/10.1016/j.rse.2005.03.009

Coops, N., M. Stanford, K. Old, M. Dudzinski, D. Culvenor, C. Stone, 2003: Assessment of Dothistroma needle blight of Pinus radiata using airborne hyperspectral imagery. Ecology and Epidemiology 93(12): 1524-1532. https://doi. org/10.1094/PHYTO.2003.93.12.1524

Culvenor, D.S., 2002: TIDA: an algorithm for the delineation of tree crowns in high spatial resolution remotely sensed imagery. Computers and Geosciences 28(1): 33-44. https://doi.org/10.1016/S0098-3004(00)00110-2

Darvishsefat, A.A., T.W. Kellenberger, K.I. Itten, 2002: Application of hyperspectral data for forest stand mapping. Symposium on geospatial theory, processing and applications, Ottawa, p. 5.

De Jong, S.M., G.F. Epema, 2001: Imaging spectrometry for surveying and modeling land degradation. U: F.D. van der Meer, S.M. de Jong (ur.): Imaging spectrometry: basic principles and prospective applications, Kluwer Academic Publishers, Dordrecht, The Netherlands, 65-86. https://doi.org/10.1007/978-0-306-47578-8
Deguise, J.C., K. Staenz, J. Lefebvre, 1999: Agricultural applications of airborne hyperspectral data - Weed detection. International Airborne Remote Sensing Conference and Exhibition, $4^{\text {th }} / 21^{\text {st }}$ Canadian Symposium on Remote Sensing, Ottawa, Canada; United States, 21-24 June 1999, 352-358.

Elhadi, A., O. Mutanga, 2009: Spectral discrimination of papyrus vegetation (Cyperus papyrus L.) in swamp wetlands using field spectrometry. ISPRS Journal of Photogrammetry and Remote Sensing 64(6): 612-620. https:// doi.org/10.1016/j.isprsjprs.2009.04.004

Elvidge, C.D., 1990: Visible and infrared reflectance characteristics of dry plant materials. International Journal of Remote Sensing 11(10): 1775-1795. https://doi. org/10.1080/01431169008955129

Elvidge, C.D., F.P. Portigal, D.A. Mouat, 1990: Detection of trace quantities of green vegetation in 1989 AVIRIS data. Second Airborne Visible/Infrared Imaging Spectrometer (AVIRIS) Workshop, JPL, Pasadena, CA, 35-41.

Ferretti, M., 1997: Forest health assessment and monitoring-issues for consideration. Environ Mon it Assess. 48: 45-72. https://doi.org/10.1023/A:1005748702893

Goetz, A.F.H. (ed.), 1995: Imaging spectrometry for remote sensing: vision to reality in 15 years. Proceedings of SPIE Society of Optical Engineers, Orlando, Florida, vol. 2480: 2-13.

Green, E.P., C.D. Clark, P.J. Mumby, A.J. Edwards, A.C. Ellis, 1998: Remote sensing techniques for mangrove mapping. International Journal of Remote Sensing 19(5): 935-956. https://doi.org/10.1080/014311698215801

Grove, C.I., S.J. Hook, E.D. Paylor, 1992: Laboratory reflectance spectra for 160 minerals 0.4-2.5 micrometers. JPL Publication 92-2: 394. http://hdl.handle.net/2014/40148

Held, A., C. Ticehurst, L. Lymburner, N. Williams, 2003: High resolution mapping of tropical mangrove ecosystems using hyperspectral and radar remote sensing. International Journal of Remote Sensing 24(13): 27392759. https://doi.org/10.1080/0143116031000066323

Huber, S., M. Kneubühler, N.E. Zimmermann, K. Itten, 2005: Potential of spectral feature analysis to estimate nitrogen concentration in mixed canopies. $4^{\text {th }}$ Workshop on Imaging Spectroscopy. Warsaw, April 27-29 2005, 1-9.

Idowu, O.J., H.M. van Es, G.S. Abawi, D.W. Wolfe, J.I. Ball, B.K. Gugino, B.N. Moebius, R.R. Schindlbeck, A.V. Bilgili, 2008: Farmer-oriented assessment of soil quality using field, laboratory, and VNIR spectroscopy methods. Plant and Soil 307(1-2): 243-253. https://doi.org/10.1007/s11104-007-9521-0

Korb, A.R., P. Dybwad, W. Wadsworth, J.W. Salisbury, 1996: Portable FTIR spectrometer for field measurements of radiance and emissivity. Applied Optics 35: 1679-1692. https://doi.org/10.1364/AO.35.001679

Kumar, L., 1998: Modeling forest resources using geographical information system and hyperspectral remote sensing. Unpublished PhD Thesis, University of New South Wales, Sidney. 
Kumar, L., K. Schmidt, S. Dury, A. Skidmore, 2001: Imaging spectrometry and vegetation science. U: F.D. van der Meer, S.M. de Jong (ur.): Imaging Spectrometry: basic principles and prospective applications, Kluwer Academic Publishers, Dordrecht, The Netherlands, 111-155.

Lawrence, R., M. Labus, 2003: Early detection of Douglas fir beetle infestation with subcanopy resolution hyperspectral imagery. Western Journal of Applied Forestry 18(3): 202-206. https://doi.org/10.1093/wjaf/18.3.202

Li, L., S. L. Ustin, M. Lay, 2005: Application of AVIRIS data in detection of oil-induced vegetation stress and cover change at Jornada, New Mexico. Remote Sensing of Environment 94: 1-16. https://doi.org/10.1016/j.rse.2004.08.010

Li, Q., X. He, Y. Wang, H. Liu, D. Xu, F. Guo, 2013: Review of spectral imaging technology in biomedical engineering: achievements and challenges, Journal of Biomedical Optics 18(10), 100901. 28 p. https://doi.org/10.1117/1. JBO.18.10.100901

Lucas, R., A. Rowlands, O. Niemann, R. Merton, 2004: Hyperspectral sensors and applications. U: P.K. Varshney, M.K. Arora (ur.): Advanced Image Processing Techniques for Remotely Sensed Hyperspectral Data. Springer-Verlag Berlin - Heidelberg - New York, 11-49. https://doi. org/10.1007/978-3-662-05605-9

Mannheim, S., K. Segl, B. Heim, H. Kaufmann, 2004: Monitoring of lake water quality using hyperspectral CHRIS-PROBA Data. Proceedings of the $2^{\text {nd }}$ CHRIS/Proba Workshop. 28-30 April 2004 ESRIN, Frascati, Italy.

Mirik, M., G.J. Michaels jr., S. Kassymzhanova-Miril, N.C. Elliott, V. Catana, D.B. Jones, R. Bowling, 2006: Using digital image analysis and spectral reflectance data to quantify damage by green bug (Hemiptera: Aphididae) in winter wheat. Computers and electronics in agriculture 51(1-2): 86-98. https://doi.org/10.1016/j.compag.2005.11.004

Neuenschwander, A.L., M.M. Crawford, M.J. Provancha, 1998: Mapping of coastal wetlands via hyperspectral AVIRIS data. Geoscience and Remote Sensing Symposium Proceedings, 1998. IGARSS '98. 1998 IEEE International. 6-10 July 1998, 189-191. https://doi.org/10.1109/IGARSS.1998.699507

Ong, C., T. Cudahy, M. Caccetta, P. Hick, M. Piggott, 2001: Quantifying dust loading on mangroves using hyperspectral techniques. International Geoscience and Remote Sensing Symposium (IGARSS), Sydney, Australia, CD. https://doi.org/10.1109/igarss.2001.976136

Pernar, R., M. Bajić, D. Vuletić, M. Idžojtić, M. Ančić, A. Seletković, 2005: Aerial high resolution imaging of the mistletoe for the assessment of forest decline in fir stands. Proceedings on CD of the ISPRS Hannover Workshop 2005, High-Resolution Earth Imaging for Geospatial Information, Vol. 36, Hannover, Germany, May 17-20, 2005.

Piwowar, J. M., 1999: Assessing annual forest ecological change in western Canada using temporal mixture analysis of regional scale AVHRR imagery over a 14 year period. Wa- terloo Laboratory for Earth Observations, University of Waterloo, Waterloo, Ontario, Canada, presentation.

Pontius, J., M. Martin, L. Plourde, R. Hallett, 2005: Using hyperspectral technologies to map hemlock decline: Pre-visual decline assessment for early infestation detection. Third symposium on Hemlock woolly Adelgid in the Eastern United States, Asheville, North Carolina, 73-87.

Robichaud, P.R., J.A. Zamudio, 2004: Hyperspectral imaging over forest fires. Report. http://www.earthsearch. com/pdf/forestfires.pdf

Salisbury, J.W., D.M. D'Aria, E. Jarosewich, 1991a: Midinfrared (2.5-13.5 micrometers) reflectance spectra of powdered stony meteorites. Icarus 92: 280-297. https://doi. org/10.1016/0019-1035(91)90052-U

Salisbury, J.W., L.S. Walter, N. Vergo, D.M. D'Aria, 1991b: Infrared (2.1- 25 micrometers) Spectra of Minerals. Johns Hopkins University Press, p. 294. https://doi.org/10.3133/ ofr87263

Salisbury, J.W., A. Wald, D.M. D'Aria, 1994: Thermal-infrared remote sensing and Kirchhoff's law 1. Laboratory measurements. Journal of Geophysical Research 99: 11897-11911. https://doi.org/10.1029/93JB03600

Shippert, P., 2003: Introduction to hyperspectral image analysis. Online Journal of Space Communication, Issue no. 3: Remote Sensing of Earth via Satellite, p. 12. https:// spacejournal.ohio.edu/pdf/shippert.pdf

Stone, C., C. Mohammed, 2017: Application of remote sensing technologies for assessing planted forests damaged by insect pests and fungal pathogens: A Review. Current Forestry Reports 3: 75-92. https://doi.org/10.1007/s40725-017-0056-1

Ticehurst, C., L. Lymburner, A. Held, C. Palylyk, D. Martindale, W. Sarosa, S. Phinn, M. Stanforf, 2001: Mapping tree crowns using hyperspectral and high spatial resolution imagery. Proceedings of $3^{\text {rd }}$ International Conference on Geospatial Information in Agriculture and Forestry, Denver, Colorado, CD.

Tsai, F., C.F. Chen, 2004: Detecting invasive plants using hyperspectral and high resolution satellite images. Geo-Imagery Bridging Continents $20^{\text {th }}$ ISPRS Congress Commission 7. July 12-23, 2004, Istanbul, Turkey, p. 6.

Van Aardt, J.A.N., R.H. Wynne, 2001: Spectral separability among six southern tree species. Photogrammetric Engineering and Remote Sensing 67(12): 1367-1375.

Van der Meer, F.D., S.M. de Jong, 2001: Introduction. U: F.D. van der Meer, S.M. de Jong (ur.), Imaging Spectrometry: basic principles and prospective applications, Kluwer Academic Publishers, Dordrecht, The Netherlands. https://doi.org/10.1007/978-0-306-47578-8

Veys, C., J. Hibbert, D. Phillip, B. Grieve, 2017: An ultralow-cost active multispectral crop diagnostics device. Paper presented at IEEE Sensors 2017 Conference, Glasgow, United Kingdom, 1005-1007. https://doi.org/10.1109/ ICSENS.2017.8234211 


\section{Abstract}

\section{Hyperspectral Sensors and Application in Forestry}

From the very beginning of the development of remote sensing, humans have been trying to create a tool to study the Earth's dynamic surface and its phenomena. With the advancement of technology, first for the military and then for research purposes, sensors have been developed to collect data by recording the electromagnetic spectrum (multi and hyperspectral). From the moment they became available for civilian use, the potential benefits of using hyperspectral data became apparent. The development of hyperspectral systems followed the development of computer technologies and the progress of software for processing a large number of collected data.

Nowadays, hyperspectral sensors are increasingly being used for various purposes: ecosystem study, atmosphere, climate, hydrology, mineral exploitation, land use, land cover, and vegetation. Thanks to the wide variety of information they provide, hyperspectral sensors have large application potential in environmental monitoring and management. Also, they help to improve management and better decision-making at early problem defining.

The first application of hyperspectral sensors in Croatian forestry relates to the European Community program of 2005, when the first imaging with a line hyperspectral scanner was conducted. Within the conducted imaging, the first spectral curves of Silver fir and White berried mistletoe were separated. On the basis of this separation, for the first time, the difference between these two species was established. In other words, hyperspectral imagery was used to distinguish shrubs of semi-parasitic species within the host canopy. Also, procedures for large-area imaging were defined.

Keywords: hyperspectral sensors, forestry, spectral signatures

Primljeno (Received): 8. 10. 2019.

Prihvaćeno (Accepted): 21. 11. 2019.
Adrese autorâ - Authors' addresses:

Doc. dr. sc. Mario Ančić*

e-pošta:mancic@sumfak.hr

Prof. dr. sc. Renata Pernar

e-pošta: rpernar@sumfak.hr

Izv. dr. sc. Ante Seletković

e-pošta: aseletkovic@sumfak.hr

Dr. sc. Jelena Kolić

e-pošta: jkolic@sumfak.hr

Šumarski fakultet Sveučilišta u Zagrebu

Zavod za izmjeru i uređivanje šuma

Svetošimunska 25

10000 Zagreb

HRVATSKA

Fran Bono Cindrić, univ. bacc. ing. silv.

e-pošta: bono2503@gmail.com

Gojka Šuška 12

47240 Slunj

HRVATSKA

${ }^{*}$ Glavni autor - Corresponding author 